\title{
A novel technique for the treatment of post operative retro-rectal haematoma: two case reports
}

\author{
Maruthesh Gowda Chikkappa*, Charles Morrison, Jay Gokhale, Ralph Antrum
}

\begin{abstract}
Rectal bleeding following any form of rectal surgery is a well recognised complication $1,2,3 \& 4$. However retrorectal bleeding and tracking which then presents as rectal bleeding has not been reported in the literature. We describe a novel way of dealing with this technically difficult post-operative complication.

We present two cases of significant rectal bleeding (one following STARR procedure and other after Delormes procedure). Both patients had to be taken back to theatre due to continuing, significant bleeding. Examination under anaesthesia on both occasions revealed a posterior boggy swelling, with an opening which admitted a finger. In both cases clots were evacuated and a corrugated drain was inserted in to the retro rectal space.

The authors believe that following any form of rectal surgery, retro-rectal bleeding with tracking can present as rectal bleeding. Treatment in the form of EUA and insertion of corrugated helped to resolve the problem.

We present both cases and literature review of the complications of stapled haemorrhoidopexy.
\end{abstract}

\section{Introduction}

Post operative rectal bleeding after stapled transanal rectal resection (STARR) has been widely reported. Management of this common but potentially life threatening postoperative complication remains a technically difficult challenge. We describe a novel way of treating this complication.

\section{Case presentation Case report 1}

A 49-years-old Caucasian, British lady underwent stapled transanal rectal resection (STARR) procedure for second degree haemorrhoids and mucosal prolapse confirmed at the time of operation. Patient was discharged same day with analgesics and laxatives.

Patient presented following day complaining of inability to urinate and was found to have residual of $1300 \mathrm{ml}$ for which she was catheterised and hospitalised. On examinations patient was haemodynamically stable but noted to have haemoglobin $(\mathrm{Hb})$ of $9.3 \mathrm{gms} / \mathrm{lt}$ down from $14.3 \mathrm{gms} / \mathrm{lt}$ recorded pre operatively. Ultrasound

\footnotetext{
* Correspondence: dr_gcm@yahoo.com

Department of General Surgery, Bradford Royal Infirmary, Bradford, BD9 6RJ,
} UK
(USS) of abdomen and pelvis requested after review by urologist was normal. On the following day blood tests revealed $\mathrm{Hb}$ of 8.1 and digital rectal examination (DRE) done by the colorectal consultant revealed extensive bruising around perineum, both sides of labia and thickening of rectal wall with old blood on gloves. Staple line was not felt, as examination could not be completed due to discomfort. Oral cefadrine and metronidazole were prescribed. Vital signs were blood pressure of 96/ 57 , pulse of 97 , respiratory rate of 24 and saturation of $97 \%$ and temperature of $36.5^{\circ}$.

Upon review by the operating surgeon following day the patient was taken for examination under anaesthetic (EUA). At the time of EUA, patient was found to have boggy mass posteriorly with small defect at 6 o' clock position below staple line through which blood clots were coming out. Staple line was intact. Blood was evacuated through the defect. Post operative plan was to continue antibiotics and repeat EUA 3 days later. In the interim $\mathrm{Hb}$ remained stable.

Repeat EUA confirmed the defect which had been previously noted. Again clots were evacuated and the cavity was irrigated with $700 \mathrm{mls}$ of saline. This time a corrugated drain was inserted. Antibiotics were changed to Piptazobactam because of concerns of infection, on \\ C Biomed Central}

(c) 2010 Chikkappa et al; licensee BioMed Central Ltd. This is an Open Access article distributed under the terms of the Creative Commons Attribution License (http://creativecommons.org/licenses/by/2.0), which permits unrestricted use, distribution, and reproduction in any medium, provided the original work is properly cited. 
the advice of microbiologist and 2 units of packed cells were transfused because of sings of continued bleeding, pulse rate of 112 and blood pressure of 87/56 intraoperatively.

Patient was discharged home after full recovery a week later and remained well on follow up.

\section{Case report 2}

An 84-years-old Caucasian, British lady had a routine Delormes procedure and stayed overnight because of social reasons. An episode of per rectal (PR) bleeding with low blood pressure of $88 / 56$, pulse of 72 , respiratory rate of 18 , saturation of $99 \%$ and temperature of $37^{\circ}$ was reported next day. $\mathrm{Hb}$ remained stable at 9.3 gms/lt and was kept in hospital for observation. Two days later another episode of PR bleeding associated with shortness of breath was reported. Vital measurements at this time were blood pressure of $98 / 66$, pulse of 90 , respiratory rate of 26 , saturation of $94 \%$ and temperature was $36^{\circ}$

Digital rectal examination (DRE) at that time showed extensive bruising and old blood coming from rectum. Electrocardiogram and chest radiograph did not show any abnormality and again $\mathrm{Hb}$ remained stable. After another episode of PR bleeding on next day patient was taken for EUA. At the time of EUA, she was found to have boggy swelling at 9 o' clock position with small defect. Suture line was intact distal to it.

From the experience of the first case, cavity was irrigated with normal saline and corrugated drain was inserted. Oral antibiotics were started. Drain was taken out 4 days later and patient was allowed home the following day.

\section{Discussion}

Stapled haemorrhoidopexy is a widely advocated operation because of shorter hospital stay and less discomfort but it is associated with different complications compared to traditional haemorrhoidectomy [1].

Post operative rectal bleeding after any rectal procedure is common and incidence varies from $0.01 \%$ to $25 \%$ [1]. and is technically difficult problem to deal with. Staple line bleeding points needing haemostasis at the time of surgery [1], have been reported since the original description of stapled haemorrhoidopexy by Longo at $6^{\text {th }}$ World Congress of Endoscopic Surgery in 1998. The need to take patient back to theatre for bleeding within a few hours of stapled haemorrhoidopexy is reported to be around 3\% [2]. In these cases bleeding is usually from arteriolar vessels of the submucosa, which could be stopped by local haemostasis [3]. It could also be due to staples not achieving proper haemostasis or folded mucosa in the staple line.

Post operative bleeding in these cases is potentially a very serious complication, which may be under- estimated. Timely and appropriate assessment and possible intervention by an experienced surgeon is needed. Serious complications reported include continued rectal bleeding up to 12 months [4], perirectal haematoma leading to hypovolumic shock [5], uncontrollable intra abdominal bleeding needing low anterior resection [6], faecal peritonitis from rectal perforation [7] and death [8].

Though flavonoids were initially advocated for the reduction of bleeding and pain after stapled haemorrhoidectomy, Mlakar B [9], showed they did not make significant difference. Complications due to staple line failure leading either to hemorrhage or leakage can nowadays be treated with coagulation materials such as glues, however large trials rest to prove their value [10].

Author thinks that retro rectal bleeding tracks down in retro rectal space and form boggy mass which opens up and presents as rectal bleeding. This kind of bleeding is better treated by the novel technique described.

\section{Conclusion}

Meticulous haemostasis achieved at the time of surgery is the most important factor in preventing post operative bleeding. In our report we have described a novel technique for the management of a not infrequent post operative complication that can be technically difficult to treat and have potentially serious consequences.

\section{Consent}

Written informed consent was obtained from the patient for publication of this case report and accompanying images. A copy of the written consent is available for review by the Editor-in-Chief of this journal.

Authors' contributions

GCM and CM wrote the case report including references. JAG and RA read suggested the changes. All authors read and agreed the final manuscript.

\section{Competing interests}

The authors declare that they have no competing interests.

\section{Received: 30 November 2009}

Accepted: 1 February 2010 Published: 1 February 2010

\section{References}

1. Mehigan BJ, Monson JRT, Hartley JE: Stapling procedure for haemorrhoids versus Milligan Morgan haemorrhoidectomy: a controlled trial. Lancet 2005, 355:782-785.

2. Bikhchandani J, Agarwal PN, Kant R, Malik VK: Randomized controlled trial to compare the early and mid-term results of stapled versus open hemorrhoidectomy. Amr J Surg 2005, 189(1):56-60.

3. Koh DCS, Denis MO, Wong C, Wong KS: Stapled haemorrhoidectomy: bothersome staple line bleeding. Asian J Surg 2005, 28:193-197.

4. Drummond R, Wright DM: Letter to editor, continued rectal bleeding following stapled haemorrhoidectomy. Colorectal Dis 2007, 9:669-670.

5. Hildalgo GLA, Heredia BA, Fantova MJ, Sunol SX: Perirectal haematoma and hypovolaemic shock after rectal stapled mucosectomy for haemorrhoids. Int J Colorectal Dis 2005, 20:471-472. 
6. Blouhos K, Vasiliadis K, Tsalis K, Botsisos D: Uncontrollable intra bdominal bleeding necessitating low anterior resection of rectum after stapled hemorrhoidopexy: Report of a case. Surg Today 2007, 37:254-257.

7. Wong LY, Jiang KE, Chang SH, Lin JK: Rectal perforation: a life-threatening complication of stapled hemorrhoidectomy: report of a case. American society of colon and rectal surgeons 2003, 46:116-117.

8. Maw A, Eu KW, Seow-Choen F: Retroperitoneal sepsis complicating stapled haemorrhoidectomy: report of a case and review of the literature. Dis Colon Rectum 2001, 72:180-185.

9. Mlakar B, Kosorok P: Flavonoids to reduce bleeding and pain after stapled hemorrhoidopexy: a randomized controlled trial. Middle European Journal of Medicine 2005, 15-16:558-560.

10. Anghelacopoulos SE, Tagarakis Gl, Pilpilidis I, Kartsounis C, Chryssafis G: Albumin-gluteraldehyde bioadhesive ("Bioglue") for prevention of postoperative complications after stapled haemorrhoidopexy: a randomized controlled trial. Middle European Journal of Medicine 2006, 1516:469-472.

doi:10.1186/1757-1626-3-42

Cite this article as: Chikkappa et al:: A novel technique for the treatment of post operative retro-rectal haematoma: two case reports. Cases Journal 2010 3:42.

\section{Submit your next manuscript to BioMed Central} and take full advantage of:

- Convenient online submission

- Thorough peer review

- No space constraints or color figure charges

- Immediate publication on acceptance

- Inclusion in PubMed, CAS, Scopus and Google Scholar

- Research which is freely available for redistribution

Submit your manuscript at www.biomedcentral.com/submit
C Biomed Central 